\title{
Airline Business Models and Networks: Regulation, Competition and Evolution in Aviation Markets
}

\author{
DAVID GILLEN * \\ University of British Columbia
}

\begin{abstract}
This paper examines the evolution of airline business models and network structure decisions in the passenger aviation industry. The paper reviews the growth of hub-and-spoke networks as the dominant business model following deregulation in the latter part of the $20^{\text {th }}$ century, followed by the emergence of low cost carriers as a global phenomenon at the end of the century. The paper highlights the link between airline business strategies and network structures, and examines the resulting competition between divergent network structure business models. In this context, we discuss issues of market structure stability and the role played by competition policy.
\end{abstract}

\section{Introduction}

Taking a snapshot of the commercial passenger aviation industry in 2006, the signals on firm survivability and industry equilibrium are mixed; some firms continue to be under severe stress while others are succeeding as the current environment of traffic growth has provided a respite from the previous three years. ${ }^{1}$ In the US, we find United Airlines continuing in Chapter 11 and US Airways emerging from Chapter 11 via a merger with America West. We find American Airlines recovering well after having reported the largest financial loss in US airline history two years previous, while Delta and Northwest Airlines along with smaller carriers like Alaska and several regional carriers are restructuring and employing cost reduction strategies. We also find Continental Airlines surviving after having been in and out of chapter 11 in recent years, while Southwest Airlines continues to be profitable as do other so called low cost carriers as Jet Blue. In Canada, we find Air Canada having emerged from CCAA bankruptcy protection (the Canadian version of chapter 11) and doing well, after reporting losses of over $\$ 500$ million for the year 2002 and in March 2003. ${ }^{2}$ Meanwhile, WestJet like Southwest, continues to show profitability after a stumble to a small loss in 2003, while two new carriers, Jetsgo and CanJet (reborn), have exited the market.

Looking at Europe, the picture is much the same, with large full-service airlines (FSAs hereafter) such as British Airways and Lufthansa recovering to profitability after

\footnotetext{
* Centre for Transportation Studies, Sauder School of Business, University of British Columbia, Vancouver, Canada. Email: david.gillen@CTS.ubc.ca

${ }^{1}$ This scenario is true in most other countries as well; Australia, New Zealand and the EU.

${ }^{2}$ CCAA refers to the Companies Creditors Arrangement Act .
} 
sustaining losses and suffering financial difficulties, Air France-KLM continue their seeming well executed merger while value-based airlines (LCC's) like Ryanair and EasyJet continue to grow and prosper. The LCC sector has seen consolidation, Air Berlin purchasing Deutche BA and Hapagloyd Express being taken back into the umbrella of the charter company. Asian air travel markets continue to perform better than in North America with air traffic growth above that forecast.

In this paper, we examine the evolution of air transport networks after economic deregulation, and the connection between networks and business strategies, in an environment where regulatory changes continue to change the rules of the game. This introductory section continues with a descriptive account and analysis of developments in the aviation sector as economic liberalization expanded within and across countries. Section 2 describes and contrasts distinguishing elements of the two dominant but divergent business models: the traditional FSA business model, which is tied to the use of hub-and-spoke networks and the LCC business model, which utilizes a point-to-point network structure. ${ }^{3}$ In section 3 , we review and develop some insights from the economics of networks applied to airline competition and in section 4, we discuss two issues relating to competition and regulation in commercial passenger aviation: stability in market structure and the application of competition policy. Some concluding remarks are offered in section 5 .

\subsection{Industry and business model evolution}

The deregulation of the US domestic airline industry in 1978 was the precursor of similar moves by most other developed economies in Europe (beginning 1992-1997), Canada (beginning in 1984), Australia (1990) and New Zealand (1986). ${ }^{4}$ The argument was that the industry was mature and capable of surviving under open market conditions subject to the forces of competition rather than under economic regulation. ${ }^{5}$

Prior to deregulation in the US, some airlines had already organized themselves into hub-and-spoke networks. Delta Airlines, for example, had organized its network into a hub at Atlanta with multiple spokes. Other carriers had evolved more linear networks with generally full connectivity and were reluctant to shift to hub-and-spoke for two reasons. First, regulations required permission to exit markets and such exit requests would likely lead to another carrier entering to serve "public need". Secondly, under regulation, it was

\footnotetext{
${ }^{3}$ The LCC (low cost carrier) model has evolved with some LCCs sticking to their original cost focus (Ryanair, Southwest) and others focusing on customer value (LCCs) as Air Berlin and JetBlue while others have morphed in "value focused carriers" (VFC) and are looking more like the old style legacy carriers.

${ }^{4}$ Canada's deregulation was not formalised under the National Transportation Act until 1987. Australia and New Zealand signed an open skies agreement in 2000, which created a single Australia-New Zealand air market across the Tasman but not including the right of cabotage. Canada and the US signed an open skies agreement in 1996 although not nearly so liberal as the Australian-New Zealand one; however the one signed in 2007 is significantly more liberal with extensive 5th freedom rights.

${ }^{5}$ In contrast to deregulation within domestic borders, international aviation has been slower to introduce unilateral liberalization. Consequently, the degree of regulation varies across routes, fares, capacity, entry points (airports) and other aspects of airline operations depending upon the countries involved.. The US-UK, German, Netherlands and Korea bilaterals are quite liberal, for example. In some cases, however, most notably in Australasia and Europe, there have been regional air trade pacts, which have deregulated markets between and within countries. The open skies agreement between Canada and the US is similar to these regional agreements.
} 
not easy to achieve the demand side benefits associated with networks because of regulatory barriers to entry. In the era of economic regulation, the choice of frequency and ancillary service competition were a direct result of being constrained in fare and market entry competition. With deregulation, airlines gained the freedom to adapt their strategies to meet market demand and to reorganize themselves spatially. Consequently, hub-andspoke became the dominant choice of network structure.

The hub-and-spoke network structure was perceived to add value on both the demand and cost side. On the demand side, passengers gained access to broad geographic and service coverage, with the potential for frequent flights to a large number of destinations. ${ }^{6}$ Large carriers provided lower search and transactions costs for passengers and reduced through lower time costs of connections. They also created travel products with high convenience and service levels - reduced likelihood of lost luggage, in-flight meals and bar service for example. The FSA business model thus favoured high service levels which helped to build the market at a time when air travel was an unusual or infrequent activity for many individuals. Building the market not only meant encouraging more air travel but also expanding the size of the network which increased connectivity and improved aircraft utilization; again a demand side attraction.

On the cost side, the industry was shown to have few, if any, economies of scale but there were significant economies of density. Feeding spokes from smaller centres into a hub airport enabled full service carriers to operate large aircraft between major centres with passenger volumes that lowered costs per available seat. There was also found to be significant returns to spatial scope (Basso and Jara-Diaz, 2006) whereby cost economies may arise from both network size and network structure, where economies of spatial scope examines network partitions.

An early exception to the hub-and-spoke network model was Southwest Airlines. In the US, Southwest Airlines was the original "low cost carrier" (LCC) representing a strategy designed to build the market for consumers whose main loyalty is to low price travel. This proved to be a sustainable business model and Southwest's success was to create a blueprint for the creation of other LCC's around the world. The evolution has also been assisted by the disappearance of charter airlines with deregulation as FSA's served a larger scope of the demand function through their yield management system.

Meanwhile, benefits of operating a large hub-and-spoke network in a growing market led to merger waves in the US (mid-1980s) and in Canada (late-1980s) and consolidation in other countries of the world. Large firms had advantages from the demand side, since they were favoured by many passengers and most importantly by high yield business passengers. They also had advantages from the supply side due to economies of density and economies of stage length. ${ }^{7}$ In most countries other than the US, there tended to be high industry concentration with one or at most two major carriers. It was also true that except in the US, there was a national (or most favoured) carrier that was privatized at the time of deregulation or soon thereafter. However, despite these formal changes, such carriers continued to be favoured by their respective governments.

Looking at aviation markets since the turn of the century, casual observation would suggest that a combination of market circumstances created an opportunity for the propagation of the LCC business model - with a proven blueprint provided by Southwest Airlines. However, a question remains as to whether something else more fundamental has

\footnotetext{
${ }^{6}$ Like telephone networks, adding a point to a hub-and-spoke system creates $2 \mathrm{n}$ connections.

${ }^{7}$ Unit costs decrease as stage length increases but at a diminishing rate.
} 
been going on in the industry to cause the large airlines and potentially larger alliances to falter and fade. If the causal impetus of the current crisis was limited to cyclical macro factors combined with independent demand shocks, then one would expect the institutions that were previously dominant to re-emerge once demand rebounds. If this seems unlikely, it is because the underlying market environment has evolved into a new market structure, one in which old business models and practices are no longer viable or desirable; the evolution of business strategies and markets, like biological evolution is subject to the forces of selection. Airlines which cannot or do not adapt their business model to longlasting changes in the environment will disappear, to be replaced by those companies whose strategies better fit the evolved market structure. But to understand the emerging strategic interactions and outcomes of airlines, one must appreciate that in this industry, business strategies are necessarily tied to network choices.

\section{$2 \quad$ Network structure and business strategy}

The organization of production spatially in air transportation networks confers both demand and supply side network economies and the choice of network structure by a carrier necessarily reflects aspects of its business model and will exhibit different revenue and cost drivers. In this section, we outline important characteristics of the business strategy and network structures of two competing business models: the full service strategy (utilizing a hub-and-spoke network) and the low cost strategy model which operates under a partial point-to-point network structure. We also discuss the evolution of each model and the seeming central tendency where they are moving closer together than maintaining their differences.

\subsection{Hub-and-spoke networks and the full-service strategy}

The full service business model is predicated on broad service in product and in geography bringing customers to an array of destinations with flexibility and available capacity to accommodate different routings, no-shows and flight changes. The broad array of destinations and multiple spokes requires a variety of aircraft with differing capacities and performance characteristics. The variety increases capital, labour and operating costs. This business model labours under cost penalties and lower productivity of hub-and-spoke operations including long aircraft turns, connection slack, congestion, and personnel and baggage online connections. These features take time, resources and labour, all of which are expensive and are not easily avoided. The hub-and-spoke system is also conditional on airport and airway infrastructure, information provision through computer reservation and highly sophisticated yield management systems. The product is complex, a complexity demanded by only 20 percent of passengers, the operation is complex and made more susceptible to higher costs due to variance in operations and, a complex organizational structure.

The network effects that favoured hub-and-spoke over linear connected networks lie in the compatibility of flights and the internalization of pricing externalities between links in the network. A carrier offering flights from city A to city B through city $\mathrm{H}$ (a hub) is able to collect traffic from many origins and place them on a large aircraft flying from $\mathrm{H}$ to $\mathrm{B}$, thereby achieving density economies and possible spatial scope economies. In contrast, a carrier flying directly from A to B can achieve some direct density economies but more 
importantly, gains aircraft utilization economies. In the period following deregulation, density economies were larger than aircraft utilization economies on many routes, owing to the limited size of many origin and destination markets.

On the demand side, FSA's could maximize the revenue of the entire network by internalizing the externalities created by complementarities between links in the network. In our simple example of a flight from $\mathrm{A}$ to $\mathrm{C}$ via hub $\mathrm{H}$, the carrier has to consider how pricing of the AH link might affect the demand for service on the HB link. If the service were offered by separate companies, the company serving AH will take no consideration of how the fare it charged would influence the demand on the HB link since it has no right to the revenue on that link. The FSA business model thus creates complexity as the network grows, making the system work effectively requires additional features most notably, yield management and product distribution. In the period following deregulation, technological progress provided the means to manage this complexity, with large information systems and in particular, computer reservation systems. Computer reservation systems make possible sophisticated flight revenue management, the development of loyalty programs, effective product distribution, revenue accounting and load dispatch. They also drive aircraft capacity, frequency and scheduling decisions. As a consequence, the FSA business model places relative importance on managing complex schedules and pricing systems with a focus on profitability of the network as a whole rather than individual links. This system was sustainable provided all elements of the demand function were served and maintained and arbitrage among demand groups could be prevented.

The FSA business model favours a high level of service and the creation of a large service bundle (in-flight entertainment, meals, drinks, large numbers of ticketing counters at the hub etc.) which serves to maximize the revenue yields from business and long-haul travel. An important part of the business service bundle is the convenience that is created through fully flexible tickets and high flight frequencies. High frequencies can be developed on spoke routes using smaller feed aircraft, and the use of a hub with feed traffic from spokes allows more flights for a given traffic density and cost level. More flights reduce total trip time, with increased flexibility. Thus, the hub-and-spoke system leads to the development of feed arrangements along spokes. Indeed, these domestic feeds contributed to the development of international alliances in which one airline would feed another utilizing the capacity of both to increase service and pricing.

\subsection{Point-to-point networks and the low-cost strategy}

Like the FSA model, the LCC business plan creates a network structure that can promote connectivity but in contrast trades off lower levels of service, measured both in capacity and frequency, against lower fares. In all cases, the structure of the network is a key factor in the success of LCCs even in the current economic and demand downturn. LCCs tend to exhibit common product and process design characteristics that enable them to operate at a much lower cost per unit of output. ${ }^{8}$

On the demand side, LCCs have created a unique value proposition through product and process design that enables them to eliminate, or "unbundle" certain service features in exchange for a lower fare. These service feature trade-offs are typically: less frequency, no meals, no free, or any in many cases, alcoholic beverages, more passengers per flight

\footnotetext{
${ }^{8}$ Product design refers to the "look and feel" of a product, and is the most visible difference between lowcost and full service carriers to the airline passenger.
} 
attendant, no lounge, no interlining or code-sharing, electronic tickets, no pre-assigned seating, and less leg room. Most importantly, the LCC does not attempt to connect its network although there may be connecting nodes. It also has people use their own time to access the airport from longer distances and to connect to multiple flight segment itineraries. $^{9}$

There are several key areas in process design (the way in which the product is delivered to the consumer) for a LCC that result in significant savings over a full service carrier. One of the primary forms of process design savings is in the planning of point-topoint city pair flights, focusing on the local origin and destination market rather than developing hub systems. In practice, this means that flights are scheduled without connections and stops in other cities. This could also be considered product design, as the passenger notices the benefit of travelling directly to their desired destination rather than through a hub. Rather than having a bank of flights arrive at airports at the same time, lowcost carriers spread out the staffing, ground handling, maintenance, food services, bridge and gate requirements at each airport to achieve savings.

Another less obvious, but important cost saving can be found in the organization, design and culture of the company. It is worth noting at this point that the innovator of product, process, and organizational re-design is generally accepted to be Southwest Airlines. Many low-cost start-ups have attempted to replicate that model as closely as possible; however, the hardest area to replicate has proved to be the organization design and culture. $^{10}$

Extending the "look and feel" to the aircraft, there is a noticeable strategy for low-cost airlines. Successful LCCs focus on a homogeneous fleet type (mostly the Boeing 737 family of aircraft but this is changing; for example Jet Blue with A320 fleet). The advantages of a "common fleet" are numerous. Purchasing power is one - with the obvious exception of the aircraft itself, heavy maintenance, parts, supplies; even safety cards are purchased in one model for the entire fleet. Training costs are reduced - with only one type of fleet, not only do employees focus on one aircraft and become specialists, but economies of density can be achieved in training.

The choice of airports is typically another source of savings. Low-cost carriers tend to focus on secondary airports that have excess capacity and are willing to forego some airside revenues in exchange for non-airside revenues that are developed as a result of the traffic stimulated from low cost airlines. In simpler terms, secondary airports charge less for landing and terminal fees and make up the difference with commercial activity created by the additional passengers. Further, secondary airports are less congested, allowing for faster turn times and more efficient use of staff and the aircraft. The average taxi times shown in table 1 (below) are evidence of this with respect to Southwest in the US; at most major US airports taxi out time (average of 18 minutes) is 2.5 times higher than taxi-in (7minutes) time.

Essentially, LCCs have attempted to reduce the complexity and resulting cost of the product by unbundling those services that are not absolutely necessary. This unbundling extends to airport facilities as well, as LCCs struggle to avoid the costs of expensive primary airport facilities that were designed with full service carriers in mind. While the

\footnotetext{
${ }^{9}$ Southwest Airlines claims passengers will travel up to 1-2 hours to access an airport with lower fares. In Canada, WestJet has observed the same phenomena as have carriers in the UK and Germany.

${ }^{10}$ It should also be noted that the LCC model is not generic. Different low cost carriers do different things and like all businesses, we see continual redefinition of the model.
} 
savings in product design are the most obvious to the passenger, it is the process changes that have produced greater savings for the airline.

The design of low-cost carriers facilitates some revenue advantages in addition to the many cost advantages, but it is the cost advantages that far outweigh any revenue benefits achieved. These revenue advantages included simplified fare structures with 3-4 fare levels, a simple "yield" management system, and the ability to have one-way tickets. The simple fare structure also facilitates Internet booking. However, what is clearly evident is the choice of network is not independent of the firm strategy. The linear point-to-point network of LCCs allows it to achieve both cost and revenue advantages.

Table 1 below compares key elements of operations for US airlines 737 fleets. One can readily see a dramatic cost advantage for Southwest Airlines compared to FSAs. In particular, Southwest is a market leader in aircraft utilization and average taxi times.

Table 1: Aircraft utilization and operating cost of 737-300 and 737-700 fleets (3rd Q, 2001)

\begin{tabular}{|l|c|c|c|c|c|c|}
\hline Airline & Departures & $\begin{array}{l}\text { Block } \\
\text { Hours }\end{array}$ & $\begin{array}{l}\text { Flight } \\
\text { Hours }\end{array}$ & $\begin{array}{l}\text { Average } \\
\text { Stage } \\
\text { Length(miles) }\end{array}$ & $\begin{array}{l}\text { Average } \\
\text { Taxi Time } \\
\text { in } \\
\text { Minutes 11 }\end{array}$ & $\begin{array}{l}\text { Flight Cost per } \\
\text { Available Seat } \\
\text { Mile (US cents) }\end{array}$ \\
\hline Frontier & 4.5 & 11.2 & 9.8 & 933 & 19 & 5.6 \\
\hline Southwest & 7.6 & 10.5 & 8.9 & 472 & 13 & 4.0 \\
\hline ATA & 3.9 & 10.4 & 8.8 & 1,032 & 25 & 4.3 \\
\hline United & 5.0 & 9.3 & 7.5 & 639 & 22 & 8.1 \\
\hline Continental & 3.4 & 8.6 & 7.1 & 895 & 26 & 6.2 \\
\hline $\begin{array}{l}\text { America } \\
\text { West }\end{array}$ & 4.5 & 8.3 & 6.7 & 602 & 21 & 6.2 \\
\hline $\begin{array}{l}\text { US } \\
\text { Airways }\end{array}$ & 5.1 & 8.3 & 6.3 & 466 & 24 & 8.9 \\
\hline Delta & 4.6 & 7.8 & 6.1 & 546 & 22 & 7.1 \\
\hline
\end{tabular}

Source: Aviation Daily, March 27, 2002.

If one looks at the differences in the US between LCCs, like Southwest and FSAs, there is a 2:1 cost difference but this has evolved to about a 40 percent difference. This difference is similar to what is now found in Canada between WestJet and Air Canada, as well as in Europe, between most LCCs and traditional carriers. A, perhaps extreme, example is Ryanair which is one end of the LCC business model spectrum; it has a near 60 percent cost advantage, adjusted for stage length. Interestingly, the sources of the cost advantages are not anchored in any one or two places. Carriers buy the fuel and capital in the same market, and although there may be some difference between carriers due to hedging for example, these are not structural or permanent changes. The vast majority of the cost difference relates to product and process complexity. This complexity is directly tied to the design of their network structure.

\footnotetext{
${ }^{11}$ Calculated using the difference between block times, flight times and dividing by the number of departures.
} 
Table 2 compares cost drivers for FSAs and LCCs in Europe. The table shows the key underlying cost drivers and where a LCC like Ryanair has an advantage over FSAs in crew and cabin personnel costs, airport charges and distribution costs. The first two are directly linked to network design. A hub-and-spoke network is service intensive and high cost. Even distribution cost-savings are related indirectly to network design because LCCs have simple products and use passengers' time as an input to reduce airline connect costs.

Table 2:Comparison of cost drivers for LCCs and FSAs: Unit cost differences between average network carrier and Ryanair (2005)

\begin{tabular}{|lcc|}
\hline & CASM & Percentage \\
\cline { 2 - 3 } GAP between Avg. Network Carrier \& LCC & 8.1 \$/ASM & 63 \\
Labour Costs (excluding G\&A) & 2.8 & 33.3 \\
Sales and Reservations & 1.29 & 15.4 \\
Maintenace Costs & 1.09 & 12.9 \\
Ground Handling & 0.99 & 11.8 \\
Landing Fees & 0.74 & 8.8 \\
Other & 1.5 & 17.8 \\
\hline
\end{tabular}

Source: Carrier Annual Reports

In Europe, Ryanair has been a leader in the use of the Internet for direct sales and "etickets". In the US, Southwest Airlines was an innovator in "e-ticketing" and was also one of the first to initiate bookings on the Internet. LCCs avoid travel agency commissions and ticket production costs: in Canada, WestJet has stated that Internet booking account for approximately $40 \%$ of their sales, while in Europe, Ryanair claimed an Internet sales percentage of 91\% in March 2005. ${ }^{12}$ While most LCC's have adopted direct selling via the Internet, the strategy has been difficult for FSAs to respond to with any speed given their complex pricing systems. Recent moves by full service carriers in the US and Canada, and to some degree in Europe, to eliminate base commissions have proven to be an important cost saving in the distribution chains of all airlines but it has also made fares more transparent.

To some degree, LCCs have positioned themselves as market builders by creating point-to-point service in markets where it could not be warranted previously due to lower traffic volumes at higher FSA costs and fares. LCCs not only stimulate traffic in the direct market of an airport, but studies have shown that LCCs have a much larger potential passenger catchment area than FSAs. The catchment area is defined as the geographic region surrounding an airport from which passengers are derived. While an FSA relies on a hub-and-spoke network to create catchment, low-cost carriers create the incentive for each customer to create their own spoke to the point of departure. Table 3 provides a summary of the alternative airline strategies pursued in most developed economies in the world and the cost characteristics of their network.

\footnotetext{
${ }^{12}$ WestJet estimated that a typical ticket booked through their call centre costs roughly $\$ 12$, while the same booking through the Internet costs around 50 cents.
} 


\subsection{Survival of the fittest?}

The trend worldwide thus far indicates two quite divergent business strategies, yet ones that are evolving together to some degree. The entrenched FSA carriers' focuses on developing hub-and-spoke networks while new entrants seem intent on creating low-cost, point-to-point structures. The hub-and-spoke system places a very high value on the feed traffic brought to the hub by the spokes, especially the business traffic therein, thereby creating a complex, marketing intense business where revenue is the key and where production costs are high. Inventory (of seats) is also kept high in order to meet the service demands of business travellers. The FSA strategy is a high cost strategy because the huband-spoke network structure means both reduced productivity for capital (aircraft) and labour (pilots, cabin crew, airport personnel) and increased costs due to self-induced congestion from closely spaced banks of aircraft. ${ }^{13}$

Table 3: Description of strategies in the Canadian airline industry

\begin{tabular}{|c|c|c|c|c|c|}
\hline Strategy & \multicolumn{2}{|c|}{ High Cost, Full Service } & \multicolumn{3}{|l|}{ Low Cost, No Frills } \\
\hline $\begin{array}{l}\text { Network } \\
\text { Type }\end{array}$ & $\begin{array}{l}\text { Hub-and- } \\
\text { Spoke, } \\
\text { Scheduled } \\
\text { Service }\end{array}$ & $\begin{array}{l}\text { Point-to-Point, } \\
\text { Scheduled } \\
\text { Service }\end{array}$ & $\begin{array}{l}\text { Point-to-Point, } \\
\text { Charter/Scheduled }\end{array}$ & $\begin{array}{l}\text { Point-to-Point, } \\
\text { Charter }\end{array}$ & $\begin{array}{l}\text { Point-to-Point, } \\
\text { Scheduled }\end{array}$ \\
\hline Characteristics & $\begin{array}{l}\text { High Fixed } \\
\text { Costs } \\
\text { High Labour } \\
\text { Costs } \\
\text { Inflexible } \\
\text { Job Tasks } \\
\text { Full Service } \\
\text { Multiple } \\
\text { Classes } \\
\text { High } \\
\text { Frequencies }\end{array}$ & $\begin{array}{l}\text { Moderate Fixed } \\
\text { Costs } \\
\text { Moderate } \\
\text { Labour Costs } \\
\text { Moderate Job } \\
\text { Tasks } \\
\text { Flexibility } \\
\text { Full Service } \\
\text { Multiple Classes } \\
\text { Low } \\
\text { Frequencies }\end{array}$ & $\begin{array}{l}\text { Low Fixed Costs } \\
\text { Moderate Labour } \\
\text { Costs } \\
\text { Moderate Job Tasks } \\
\text { Flexibility } \\
\text { Low-end Full } \\
\text { Service } \\
\text { Single and Multiple } \\
\text { Classes } \\
\text { Low Frequencies }\end{array}$ & $\begin{array}{l}\text { Low Fixed Costs } \\
\text { Low Labour Costs } \\
\text { Flexible Job Tasks } \\
\text { Low-end Service } \\
\text { Single Class (few wider } \\
\text { seats) } \\
\text { Low Frequencies }\end{array}$ & $\begin{array}{l}\text { Low Costs } \\
\text { Lower Labour } \\
\text { Costs } \\
\text { Flexible Job } \\
\text { Tasks } \\
\text { No Frills } \\
\text { Service } \\
\text { Single Class } \\
\text { Increasing } \\
\text { Frequencies }\end{array}$ \\
\hline Example & $\begin{array}{l}\text { Air Canada } \\
\text { American, } \\
\text { United, } \\
\text { British } \\
\text { Airways, } \\
\text { JAL }\end{array}$ & Alaska Airlines & $\begin{array}{l}\text { Air Berlin } \\
\text { Air Transat }\end{array}$ & $\begin{array}{l}\text { Air Transat } \\
\text { Skyservice } \\
\text { TUI } \\
\text { Thomas Cook }\end{array}$ & $\begin{array}{l}\text { West Jet } \\
\text { CanJet } \\
\text { Ryanair } \\
\text { Southwest } \\
\text { Jet Blue }\end{array}$ \\
\hline
\end{tabular}

The FSA business strategy is sustainable as long as no subgroup of passengers can defect from the coalition of all passenger groups, and recognizing this, competition between FSAs included loyalty programs designed to protect each airline's coalition of passenger groups - frequent travellers in particular. The resulting market structure of competition between FSAs was thus a cozy oligopoly in which airlines competed on prices for some economy fares, but practiced complex price discrimination that allowed high yields on business travel. However, the vulnerability of the FSA business model was eventually revealed through the LCC strategy which (a) picked and chose only those origin-destination links that were profitable, (b) targeted price sensitive consumers and (c)

\footnotetext{
${ }^{13}$ Airlines were able to reduce their costs to some degree by purchasing ground services from third parties. Unfortunately they could not do this with other processes of the business.
} 
provided a simplified frae structure. ${ }^{14}$ The potential therefore was not for business travellers to defect from FSAs (loyalty programs helped to maintain this segment of demand) but for leisure travellers and other infrequent flyers to be lured away by lower fares. The key factors which have forced a change in the FSA model are the limits on the ability to price discriminate and the transparency offered by Internet booking and ticket distribution.

Figures 1 and 2 present schemata that summarize the contributory factors that propagated the FSA hub-and-spoke system and made it dominant, followed by the growth of the LCC strategy along with the events and factors that now threaten the FSA model.

\section{The economics of networks and airline competition}

In this section, we set out a simple framework to explain the evolution of network equilibrium and show how it is tied to the business model. The linkage will depend on how the business models differ with respect to the integration of demand conditions, fixed and variable cost and network organization.

Let three nodes $\left\{\theta_{1}, \theta_{2}, \theta_{3} ;(0,0),(0,1),(1,0)\right\}$, form the corner coordinates of an isosceles right triangle. The nodes and the sides of the triangle may thus represent a simple linear travel network that defines two "short-haul" travel links $\left[\left(\theta_{1}, \theta_{2}\right)\left(\theta_{1}, \theta_{3}\right)\right]$ and one "long-haul" link $\left(\theta_{2}, \theta_{3}\right)$.

In this travel network, the nodes represent points of entry and exit to/from the network, thus if the network is assumed to be an air travel market, the nodes represent airports rather than cities. This may be important when considering congestion or other factors affecting passenger throughput at airports.

This simple network structure allows us to compare three possible structures for the supply of travel services: a complete (fully connected) point-to-point network (all travel constitutes a direct link between two nodes); a hub-and-spoke network (travel between $\theta_{1}$ and $\theta_{2}$ require a connection through $\theta_{2}$ ) and limited (or partial) point-to-point network (selective direct links between nodes). These are illustrated in Figure 3 below.

In the network structures featuring point-to-point travel, the utility of consumers who travel depends only on a single measure of the time duration of travel and a single measure of convenience. However, in the hub-and spoke network, travel between $\theta_{1}$ and $\theta_{3}$ requires a connection at $\theta_{2}$, consequently the time duration of travel depends upon the summed distance $d_{1 c 3}=d_{12}+d_{23}=1+\sqrt{2}$. Furthermore, in a hub-and spoke network, there is

\footnotetext{
${ }^{14}$ LCCs will also not hesitate to exit a market if it is not profitable (for example, WestJet in Canada and Ryanair in EU) while FSAs are reluctant to exit for fear of missing feed traffic and beyond revenue.
} 


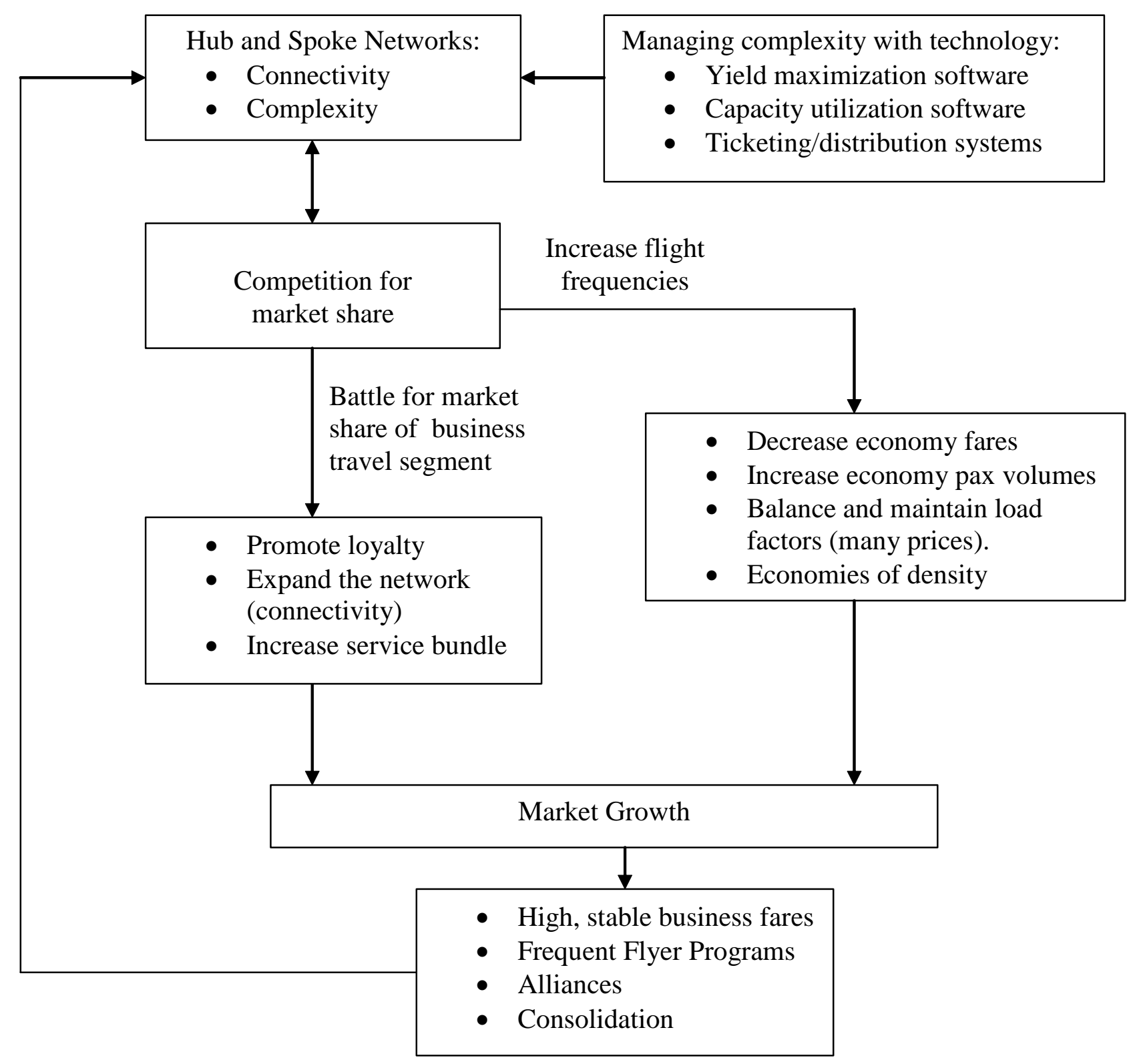

Figure 1

The rise of the FSA hub-and-spoke system 


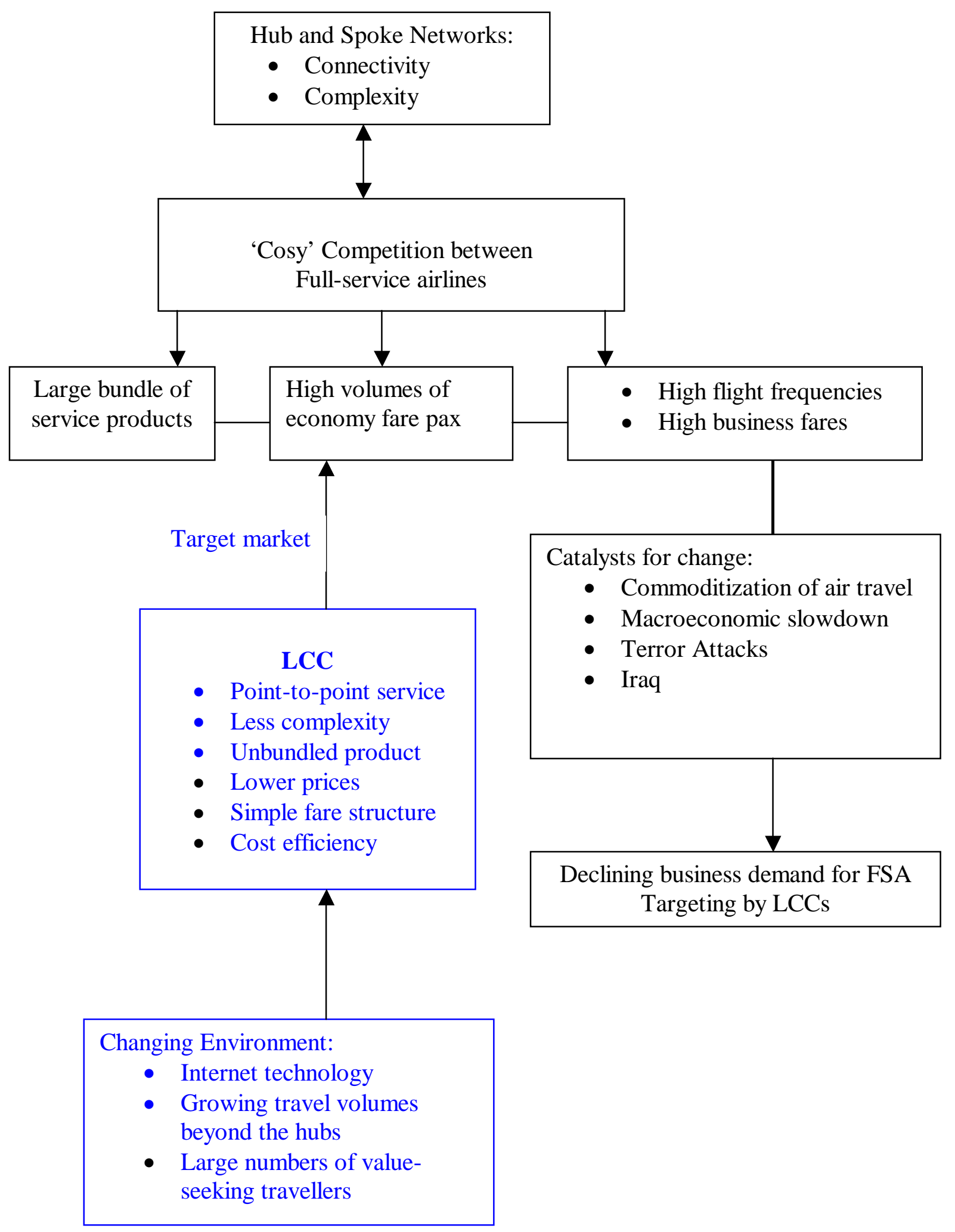

Figure2

Hub-and-spoke networks under threat: the growth of LCC point-to-point networks 
interdependence between the levels of convenience experienced by travellers. If there are frequent flights between $\theta_{1}$ and $\theta_{2}$ but infrequent flights between $\theta_{2}$ and $\theta_{3}$, then travellers will experience delays at $\theta_{2}$.

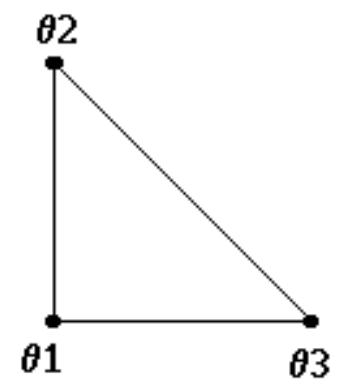

Fully connected network

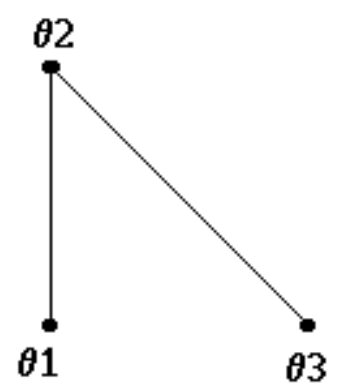

Hub-and-spoke network

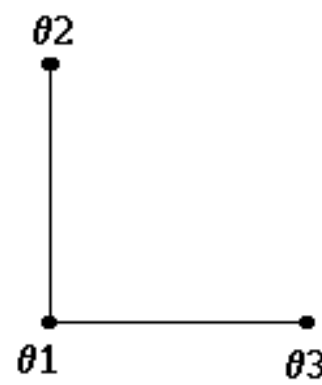

Partial point-to-point network

\section{Figure 3: Alternative network structures}

There has been an evolving literature on the economics of networks or more properly, the economics of network configuration. Hendricks et al. (1995) show that economies of density can explain the hub-and-spoke system as the optimal system in the airline networks. The key to the explanation lies in the level of density economies. However, when comparing a point-to-point network, they find the hub-and-spoke network is preferred when marginal costs are high and demand is low but given some fixed costs and intermediate values of variable costs, a point-to-point network may be preferred. Shy (2001) shows that profit levels on a fully connected (FC) network are higher than on a huband-spoke network when variable flight costs are relatively low and passenger disutility with connections at hubs is high. What has not been explained well until Pels (2000), is the relative value of market size to achieve lower costs per ASM versus economies of density. ${ }^{15}$

Pels et al. (2000) explore the optimality of airline networks using linear marginal cost functions and linear, symmetric demand functions; $M C=1-\beta Q$ and $P=\alpha-Q / 2$ where $\beta$ is a returns to density parameter and $\alpha$ is a measure of market size. The Pels model demonstrates the importance of fixed costs in determining the dominance of one network structure over another in terms of optimal profitability. In particular, the robustness of the hub-and-spoke network configuration claimed by earlier authors (for example, Hendricks et al., 1995) comes into question.

In this three-node network, the Pels model generates two direct markets and one transfer market in the hub-and-spoke network, compared with three direct markets in the fully connected network. Defining aggregate demand as $Q=Q_{D}+Q_{T}$, the profits from a hub-and-spoke network, are:

\footnotetext{
${ }^{15}$ ASM - available seat mile.
} 
(1) $\prod_{H S}=2\left(P_{D} Q_{D}+\frac{1}{2} P_{T} Q_{T}\right)-2\left(Q_{D}+Q_{T}-\frac{\beta}{2}\left(Q_{D}+Q_{T}\right)^{2}+f\right)$

while the profits of a FC network are:

(2)

$$
\Pi_{F C}=3\left(P_{F C} Q_{F C}-\left(Q_{F C}-\frac{\beta}{2} Q_{F C}^{2}+f\right)\right)
$$

More generally, for a network of size n, hub-and-spoke optimal profits are:

(3) $\prod_{H S}=(n-1)\left(P_{D} Q_{D}+\frac{(n-2)}{2} P_{T} Q_{T}\right)-(n-1)\left(Q_{D}+(n-2) Q_{T}-\frac{\beta}{2}\left(Q_{D}+(n-2) Q_{T}\right)^{2}+f\right)$

and FC profits are:

(4) $\prod_{F C}=\frac{n(n-1)}{2}\left(P_{F C} Q_{F C}-\left(Q_{F C}-\frac{\beta}{2} Q_{F C}^{2}+f\right)\right)$

Under what conditions would an airline be indifferent between network structure? The market size at which profit maximizing prices and quantities equate the profits in each network structure is:

(5) $\alpha^{*}=\frac{\beta(2 n-1)+1 \pm \sqrt{X}}{\beta(2 n-1+\beta)}$

where,

(6) $X=[1-\beta(2 n-3)](\beta-1)[2 f \beta(2 n-1+\beta)+\beta-1]$

The two possible values of $\alpha^{*}$ implied by (5) represent upper and lower boundaries on the market size for which the hub-and-spoke network and the fully connected network generate the same level of optimal profits. These boundary values are, of course, conditional on given values of the density economies parameter $(\theta)$ fixed costs $(f)$, and the size of the network (n). These parameters can provide a partial explanation for the transition from FC to hub-and-spoke network structures after deregulation.

With relatively low returns to density, and low fixed costs per link, even in a growing market, the hub-and-spoke structure generates inferior profits compared with the FC network, except when the market size $(\alpha)$ is extremely high. However, with high fixed costs per network link, the hub-and-spoke structure begins to dominate at a relatively small market size and this advantage is amplified as the size of the network grows. Importantly in this model, dominance does not mean that the inferior network structure is unprofitable. In $(\alpha, \beta)$ space, the feasible area (defining profitability) of the FC structure encompasses that of the hub-and-spoke structure. This accommodates the observation that not all airlines adopted the hub-and-spoke network model following deregulation. 
Where the model runs into difficulties is in explaining the emergence of limited pointto-point networks and the LCC model. It is the symmetric structure of the model that renders it unable to capture some important elements of the environment in which LCCs have been able to thrive. In particular, three important elements of asymmetry are missing. First, the model does not allow for asymmetric demand growth between nodes in the network. With market growth, returns to density can increase on a subset of links that would have been feeder spokes in the hub-and-spoke system when the market was less developed. These links may still be infeasible for FSAs but become feasible and profitable as independent point-to-point operations, providing an airline has low enough costs. Second, the model does not distinguish between market demand segments, therefore it cannot capture the gradual commoditization of air travel, as more consumers become frequent flyers. To many consumers today, air travel is no longer an exotic product with an air of mystery and an association with wealth and luxury. There has been an evolution of preferences that reflects the perception that air travel is just another means of getting from A to $\mathrm{B}$. As the perceived nature of the product becomes more commodity-like, consumers become more price sensitive and are willing to trade off elements of service for lower prices. ${ }^{16}$ LCCs use their low fares to grow the market by competing with other activities. Their low cost structure permits such a strategy. FSAs cannot do this to any degree because of their choice of bundled products and higher costs.

Third, the model does not capture important asymmetries in the costs of FSAs and LCCs, such that LCCs have significantly lower marginal and fixed costs. Notice that the dominance of the hub-and-spoke structure over the FC network relies in part on the cost disadvantage of a fixed cost per link, which becomes prohibitive in the FC network as the number of nodes (n) gets large. LCCs do not suffer from this disadvantage because they can pick and choose only those nodes that are profitable. Furthermore, FSAs variable costs are higher because of the higher fixed costs associated with their choice of hub-and-spoke network.

\section{Stability, competition and regulation}

It would seem that with each new economic cycle, the evolution of the airline industry brings about an industry reconfiguration. Several researchers have suggested that this is consistent with an industry structure with an "empty core", meaning non-existence of a natural market equilibrium. Button (2003) makes the argument as follows. We know that a structural shift in the composition (that is, more low-cost airlines) of the industry is occurring and travel substitutes are pushing down fares and traffic. We also observe that heightened security has increased the time and transacting costs of trips and these are

\footnotetext{
${ }^{16}$ To model a such a demand system, we need a consumer utility function of the form: $\mathrm{U}=\mathrm{U}(\mathrm{Y}, \mathrm{T}, \mathrm{V})=\gamma \mathrm{V}(\mathrm{Y}-\mathrm{P})$; where $\mathrm{Y}$ represents dollar income per period and $\mathrm{T} \in[0,1]$ represents travel trips per period. $\mathrm{V}$ is an index of travel convenience, related to flight frequency and $\mathrm{P}$ is the delivered price of travel. This reduces each consumer's choice problem to consumption of a composite commodity priced at $\$ 1$, and the possibility of taking at most one trip per period. Utility is increasing in $\mathrm{V}$ and decreasing in $\mathrm{P}$, thus travellers are willing to trade-off convenience for a lower delivered price. Diversity in the willingness to trade off convenience for price would be represented by distribution for $Y, \gamma$, and $V$ over some range of parameter values. Thus, the growth of low cost demand for air travel would be represented by an increase in the density of consumers with relatively low value of these parameters.
} 
driving away business, particularly short haul business trips. As legacy airlines shrink and die away, new airlines emerge and take up the employment and market slack.

The notion of the "empty core" problem in economics is essentially a characterization of markets where too few competitors generate supra-normal profits for incumbents, which then attracts entry. However, entry creates frenzied competition in a war-of-attrition game environment: the additional competition induced by entry results in market and revenue shares that produce losses for all the market participants. Consequently, entry and competition leads to exit and a solidification of market shares by the remaining competitors which then earn supra-normal profits that once again will attract entry.

While there is some intuitive appeal to explaining the dynamic nature of the industry resulting from an innate absence of stability in the market structure, there are theoretical problems with this perspective. ${ }^{17}$ The fundamental problem with the empty core concept is that its roots lie in models of exogenous market structure that impose (via assumptions) the conditions of the empty core rather than deriving it as the result of decisions made by potential or incumbent market participants. In particular, for the empty core to perpetuate itself, entrants must be either ill advised or have some unspecified reason for optimism. In contrast, modern industrial organization theory in economics is concerned with understanding endogenously determined market structures. In such models, the number of firms and their market conduct emerge as the result of decisions to enter or exit the market and decisions concerning capacity, quantity and price.

Part of the general problem of modeling an evolving market structure is to understand that incumbents and potential entrants to the market construct expectations with respect to their respective market shares in any post-entry market. A potential entrant might be attracted by the known or perceived level of profits being earned by the incumbent firm(s), but must consider how many new consumers they can attract to their product in addition to the market share that can be appropriated from the incumbent firm(s). This will depend in part upon natural (technological) and strategic barriers to entry, and on the response that can be expected if entry occurs. Thus, entry only occurs if the expected profits exceed the sunk costs of entry. While natural variation in demand conditions may induce firms to make errors in their predictions resulting in entry and exit decisions, this is not the same thing as an "empty core". 18

In the air travel industry, incumbent firms (especially FSAs) spend considerable resources to protect their market shares from internal and external competition. The use of frequent flier points along with marketing and branding serve this purpose. These actions raise the barriers to entry for airlines operating similar business models.

What about the threat of entry or the expansion of operations by LCCs? Could this lead to exit by FSAs? There may be legitimate concern from FSAs concerning the sustainability of the full-service business model when faced with low-cost competition. In particular, the use of frequency as an attribute of service quality by FSAs generates revenues from highvalue business travellers, but these revenues only translate into profits when there are

\footnotetext{
${ }^{17}$ The empty core theory is often applied to industries that exhibit significant economies of scale, airlines are generally thought to have limited if any scale economies but they do exhibit significant density economies. These density economies are viewed as providing conditions for an empty core. The proponents, however, only argue on the basis of FSA's business model.

${ }^{18}$ This has led some to lobby for renewed government intervention in markets or anti-trust immunity for small numbers of firms. However, if natural variability is a key factor in explaining industry dynamics, there is nothing to suggest that governments have superior information or ability to manipulate the market structure to the public benefit.
} 
enough economy travellers to satisfy load factors. So, to the extent that LCCs steal away market share from FSAs, they put pressure on the viability of this aspect of the FSA business model. The greatest threat to the FSA from a LCC is that a lower fare structure offered to a subset of passengers may induce the FSA to expand the proportion of seats offered to lower fares within the yield management system. This will occur with those LCCs like Southwest, WestJet in Canada, Virgin Blue in Australia and Easyjet that do attempt to attract the business traveller from small and medium size firms. However, carriers like Ryanair have a lower impact on overall fare structure since their frequencies are lower and the FSA can target the LCCs flights.

While FSAs may find themselves engaged in price and/or quality competition, the economics of price competition with differentiated products suggests that such markets can sustain oligopoly structures in which firms earn positive profits. This occurs because the prices of competing firms become strategic complements. That is, when one firm increases its price, the profit maximizing response of competitors is to raise price as well and there are many dimensions on which airlines can product differentiate within the FSA business model. $^{19}$

There is no question FSAs have higher seat mile costs than LCCs. The problem comes about when FSAs view their costs as being predominately fixed, hence marginal costs are very low. This "myopic" view ignores the need to cover the long run cost of capital. This, in conjunction with the argument that network revenue contribution justifies every route, lead to excessive network size and severe price discounting. ${ }^{20}$ However, when economies are buoyant, high yield traffic provides sufficient revenues to cover costs and provide substantial profit. In their assessment of the US airline industry, Morrison and Winston (1995) argue that the vast majority of losses incurred by FSAs up to that point were due to their own fare, and fare war, strategies. It must be remembered that FSAs co-exist with Southwest in large numbers of markets in the US.

The US market is a microcosm of what is to come elsewhere. The two divergent business models which have natural network structures to reflect the strategic differences in the models are now evolving together rather than apart. The cost pressure from LCCs have forced FSAs to lower costs, meaning lowering their entire cost structure so what used to be a 60 percent difference in CASM is now 40 percent. FSAs are also focused on markets which heretofore LCCs could not or would not enter given the underlying drivers of their competitive cost advantage. We see FSAs reducing their presence in domestic markets and increasing their international long-haul flying and reducing their hub activity to be connecting with less concentration of flight banks and a lower variance. At the same time, we see many LCCs expanding their service, increasing frequencies, providing "connecting airports" for multi-segment flights. Some are going into primary airports

\footnotetext{
${ }^{19}$ A standard result in the industrial organisation literature is that competing firms engaged in price competition will earn positive economic profits when their products are differentiated.

${ }^{20}$ The beyond or network revenue argument is used by many FSAs to justify not abandoning markets or charging very low prices on some routes. The argument is that if we did not have all the service from A to B, we would never receive the revenue from passengers who are travelling from B to C. In reality, this is rarely true. When FSAs add up the value of each route including its beyond revenue the aggregate far exceeds the total revenue of the company. The result is a failure to abandon uneconomic routes. The three current most profitable airlines among the FSAs, Qantas, Lufthansa and BA, do not use beyond revenue in assessing route profitability.
} 
(Virgin Blue, EasyJet, WestJet, Air Asia, for example). In some cases, we observe LCCs and legacy carriers negotiating codeshares and possible strategic relationships. ${ }^{21}$

\section{Conclusion}

The evolution of networks in today's environment will be based on the choice of business model that airlines make. This is tied to evolving demand conditions, the developing technologies of aircraft and infrastructure and the strategic choices of airlines. As we have seen, the hub-and-spoke system is an endogenous choice for FSA while the linear FC network provides the same scope for LCCs. The threat to the hub-and-spoke network is really derived from the threat to the bundled product of FSAs; this bundled product is costly. The hub-and-spoke network will only disappear if the FSA cannot implement a lower cost structure business model and at the same time provide the service and coverage that higher yield passengers demand. The higher yield passengers have not disappeared, the market has only become somewhat smaller and certainly more fare sensitive, on average. Therefore, we see FSAs migrating in their business and network structure where there is artificial (bilateral agreements) and strategic protection from excessive LCC competition; LCCs cost advantages are provided in a number of ways but an important one is a homogeneous fleet tuned for particular market size.

FSAs have responded to LCCs by trying to copy elements of their business strategy including reduced in-flight service, low cost [fighting] brands, and more point-to-point service. However, the ability of FSA to co-exist with LCC, hence hub-and-spoke networks with linear networks is to redesign their products and provide incentives for passengers to allow a reduction in product, process and organizational complexity. This is a difficult challenge since they face complex demands, resulting in the design of a complex product and delivered in a complex network, which is a characteristic of the product. For example, no-shows are a large cost for FSA and they have to design their systems in such a way as to accommodate the no-shows. This includes over-booking and the introduction of demand variability. This uncertain demand arises because airlines have induced it with service to their high yield passengers. Putting in place a set of incentives to reduce no-shows would lower costs because the complexity would be reduced or eliminated. One should have complexity only when it adds value. Another costly feature of serving business travel is to maintain sufficient inventory of seats in markets to meet the time sensitive demands of business travellers.

The hub-and-spoke structure is complex, the business processes are complex and these create costs. A hub-and-spoke network lowers productivity and increases variable and fixed costs, but these are not characteristics inherent in the hub-and-spoke design. They are inherent in the way FSA use the hub-and-spoke network to deliver and add value to their product. This is because the processes are complex even though the complexity is needed for a smaller, more demanding, higher yield set of customers. The redesigning of business processes moves the FSA between cost functions and not simply down their existing cost function but they will not duplicate the cost advantage of LCCs. The network structure

\footnotetext{
${ }^{21}$ As an example, WestJet is currently in talks with Cathay Pacific to form a strategic partnership to carry Cathay's passengers to beyond points in Canada and the US. Air New Zealand might undertake a similar arrangement with Virgin Blue in Australia.
} 
drives pricing, fleet and service strategies and the network structure is ultimately conditional on the size and preferences in the market.

What factors will affect the evolution of network design and scope? Airline markets with their networks are continuously evolving. What took place in the US ten years ago is now occurring in Europe. A "modern" feature of networks is the strategic alliance. Alliances between airlines allow them to extend their network, improve their product and service choice but at a cost. Alliances are a feature associated with FSAs and until recently not LCCs. It may be that as FSAs reposition themselves, they will make greater use of alliances. LCCs, on the other hand, will evolve their business model and their network structure forming strategic relationships more in the form of interlining to extend their market reach. Interlining is made more cost effective with modern technologies but also with airports having an incentive to offer such services rather than have the airlines provide them. Airports as modern businesses will have a more active role in shaping airline networks in the future.

\section{$6 \quad$ References}

Basso, L. and Jara-Díaz, S. (2006a) "Is Returns to Scale with Variable Network Size Adequate for Transport Industry Structure Analysis?" forthcoming, Transportation Science.

Basso, L. and Jara-Díaz, S. (2006b) "Distinguishing Multiproduct Economies of Scale from Economies of Density on a Fixed-size Transport Network," forthcoming, Networks and Spatial Economics.

Basso, L.J. and Jara-Díaz, S.R. (2005) "Calculation of Economies of Spatial Scope from Transport Cost Functions with Aggregate Output," Journal of Transport Economics and Policy, 39: 25-52.

Brueckner, J. and P. Spiller (1991) "Competition and Mergers in Airline Networks," International Journal of Industrial Organization, 9: 323-342.

Brueckner, J. (2001) "The Economics of International Codesharing: An Analysis of International Alliances,” International Journal of Industrial Organization, 19: 1475-1498

Button, K. (2003) "Empty Cores in Airline Markets," Journal of Air Transport Management, 9: 5-14

Dresner, M. and R. Windle (1996) "The Impact of Low Cost Carriers on Airport and Route Competition,” Journal of Transport Economics \& Policy, 30: 309-328.

Encaoua, D., M. Moreaux and A. Perrot (1996) "Compatibility and Competition in Airlines Demand Side Network Effects,” International Journal of Industrial Organization, 14: 701-726. 
Gillen D. and W. G. Morrison (2003) "Bundling, Integration and the Delivered Price of Air Travel: Are Low-cost Carriers Full-service Competitors?” Journal of Air Transport Management, 9: 15-23

Hendricks, K., M. Piccione and G. Tan (1995) "The Economics of Hubs: The Case of Monopoly,” Rand Journal of Economics, 28: 291-303.

Oum, T., A. Zhang and Y. Zhang (1995) “Airline Network Rivalry,” Canadian Journal of Economics, 28: 836-857.

Oum, T., J-H. Park and A. Zhang (1996) "The Effect of Airline Codesharing Agreements on Firm Conduct and International Airfares,” Journal of Transport Economics and Policy 30: 187-202.

Pels, E., Peter Nijkamp and Piet Rietveld (2000) "A Note on the Optimality of Airline Networks,” Economic Letters, 69: 429-434.

Ross T. and William Stanbury (2001) "Dealing with Predatory Conduct in the Canadian Airline Industry: A Proposal,” Canadian Competition Record, Vol. 20, 2001, 59-76.

Shy, Oz (2001) The Economics of Network Industries. Cambridge University Press: London.

Zhang, A. and X. Wei (1993) "Competition in Airline Networks, The Case of Constant Elasticity Demands,” Economic Letters, 42: 253-259. 